\title{
DE LA PROBLEMATIZACIÓN SOCIAL A LA PROBLEMATIZACIÓN PÚBLICA DEL DERECHO EDUCATIVO DE MIGRANTES INDÍGENAS EN CONTEXTOS URBANOS: la educación de los niños y niñas qom (toba) en Rosario, Santa Fe, Argentina (1986-1990)
}

\author{
Silvina Corbetta63
}

\section{RESUMEN}

La migración qom que recepciona la ciudad de Rosario, Santa Fe (Argentina) constituyó avanzados los años 80 aquello que desde el análisis de políticas públicas se denomina problema público, originado desde un problema social de progresivo dinamismo, producto de los flujos continuos de migrantes indígenas a la ciudad, y con ellos, la llegada de los niños y niñas indígenas a las escuelas criollas instaladas en cercanía de lo que fue el primer asentamiento qom. El artículo se realiza con base al marco teórico-conceptual que aportan los estudios de política pública con eje en las tres primeras fases del ciclo de la política pública: (i) surgimiento y percepción del problema, (ii) el ingreso a la agenda pública y (iii) la formulación y decisión del programa de la política. ¿Cómo se enuncia entre los actores el problema social? ¿̇Cuál fue el proceso que permitió - por primera vez- convertir en problema público, la educación de los niños migrantes e indígenas de Rosario a fines de los años 80 y de principios de los 90 ? ¿Cómo surgieron en ese contexto los actores indígenas? ¿Qué luchas, intereses de actores privados y factores colaborativos diversos confluyeron en las primeras fases del emergente ciclo de vida de la citada política? El artículo pretende analizar el modo en que se configura, fundamentalmente, la demanda educativa de migrantes internos indígenas a través de la educación. La estrategia metodológica es de corte cualitativo. La información se construyó con base a entrevistas, revisión bibliográfica y análisis de normativas.

Palabras clave: Migración Urbana Indígena. Educación Intercultural Bilingüe. Comunidad Qom.

\footnotetext{
63 Doutora em Ciências Sociais (FCSoc-UBA/Universidade de Buenos Aires). Coordenadora do Curso de Educação e Pensamento Ambiental Latinoamericano (EIE-UNSE). E-mail: silvina_corbetta@yahoo.com.ar
} 


\title{
DA PROBLEMATIZAÇÃO SOCIAL PARA A PROBLEMATIZAÇÃO PÚBLICA DO DIREITO A EDUCAÇÃO DE IMIGRANTES INDÍGENAS EM CONTEXTOS URBANOS: a \\ educação de meninos e meninas qom (toba) em Rosario, Santa Fe,
}

Argentina (1986-1990)

\section{RESUMO}

A imigração Qom na cidade de Rosario, Santa Fe (Argentina) avançou nos anos 80, e a partir da análise das políticas públicas é chamada de problema público, decorrente de um problema social de dinamismo progressivo, resultante dos fluxos contínuos de imigrantes indígenas a cidade e, com eles, a chegada de crianças indígenas para escolas criolas instaladas nas proximidades do qual foi o primeiro assentamento Qom. O artigo constituiu-se com base no referencial teórico e conceitual que fornece estudos sobre as políticas públicas com foco nas três primeiras fases da política pública: (i) o surgimento e a percepção do problema, (ii) a entrada na agenda pública e (iii) a formulação e as deliberações acerca do programa de política. Como é indicado entre os atores o problema social? Como foi o processo que permitiu pela primeira vez constitui-se como uma questão pública, a educação das crianças imigrantes indígenas de Rosário no final dos anos 80 e início dos anos 90 ? Como surgiu nesse contexto atores indígenas? Que lutas, interesses de atores privados e fatores de colaboração diversos contribuiram com o surgimento das fases iniciais do ciclo de vida política citada? $O$ artigo objetivou analisar o modo como se configura, fundamentalmente, a demanda educativa indígena de imigrantes internos através da educação. A abordagem metodológica é qualitativa. Os dados foram obtidos por meio de entrevistas, revisão da literatura e análise de documentos normativos.

Palavras-chave: Imigração Urbana Indígena. Educação Intercultural Bilíngue. Qom Comunidade.

\author{
FROM SOCIAL PROBLEMATIZATION TO PUBLIC PROBLEMATIZATION OF \\ EDUCATION RIGHTS OF INDIGENOUS MIGRANTS IN URBAN CONTEXTS: the \\ education of the boys and girls qom (toba) in Rosario, Santa Fe, Argentina
}

(1986-1990)

\begin{abstract}
The Qom migration to the city of Rosario, Santa Fe (Argentina) was advanced in the 1980s. From the analysis of public policies perspective, this phenomenon is considered a public problem, which is originated from a social problem of progressive dynamism that is the result of the continuous influxes of indigenous migrants to the city, and with them, the arrival of the indigenous children to the creole schools built near the area where the first Qom settlement was located. The
\end{abstract}


article is based on the theoretical-conceptual framework provided by public policy studies in the first three phases of the public policy cycle: (i) emergence and perception of the problem, (ii) entry into the public agenda (iii) policy formulation and decision making. How is the social problem identified among the actors? What was the process that made it possible, for the first time, to make public the education of the migrant and indigenous children of Rosario in the late 1980s and early 1990s? How did indigenous actors arise in this context? What struggles, interests of private actors and diverse collaborative factors converged in the early phases of the emerging life cycle of the policy? The article aims to analyze the way in which the educational demand of boarding indigenous migrants is fundamentally shaped through education. The methodological strategy is qualitative. The information was constructed based on interviews, bibliographic review and normative analysis.

Keywords: Indigenous Urban Migration. Intercultural Bilingual Education. Qom Community.

\section{A MODO DE INTRODUCCIÓN}

Entonces,[llegan] los niños [a la escuela] son criaturas, con toda[s] las diferencia[s] sociales, rasgos faciales, costumbres [diferentes] y la ciudad se despierta y dice: ¿̇qué hace[n]? (...) porque no existían para esta gente de la ciudad de Rosario, no existían indígenas... creyendo en la gran mentira, desde la conquista del desierto que fueron aniquiladas la[s] población[es] indígena[s] y no es así, nosotros existíamos, entonces cuando vinimos aquí, con nuestra familia, se dio un impacto social, cultural (...), político, económico, (...). Fue impactante la presencia indígena aquí en la ciudad y rotundamente negada (Maestra idónea, Escuela 1334 "Cacique Taigoyé", miembro del CIC, Barrio Empalme Graneros).

Aun cuando los primeros flujos migratorios qom proveniente del Chaco llegaran a Rosario entre fines de los 50, y principio de los 7064, la literatura en la materia y las entrevistas realizadas, coinciden en que el asunto de la migración indígena comienza a problematizarse socialmente recién con la llegada de la democracia. Así la migración qom constituyó avanzados los años 80 aquello que desde el análisis de políticas públicas se denomina problema público, originado desde un problema social de progresivo dinamismo, producto de los flujos continuos de migrantes

\footnotetext{
${ }^{64}$ El período extenso en que ubico la primera oleada migratoria indígena se debe a la falta de coincidencia en la literatura respecto al momento en que comienzan a llegar los qom a Rosario. En la introducción no obstante, recogí varias lecturas con las que reconstruí la historia de los distintos flujos. Una hipótesis al respecto -que dejé planteada también en la introducción- es que los investigadores de la época permanecían encuadrados en la teoría de clases, con lo cual veían "campesinos" en lugar de "migrantes indígenas" (TAMAGNO y MAFFIA, 2011). Esto desembocó en la invisibilización de la cuestión étnica hasta entrado el actual período democrático en Argentina (a partir de 1983).
}

Revista Exitus, Santarém/PA, Vol. 7, № 1, p. 161-178, Jan/Abr 2017. 
indígenas a la ciudad, y con ellos, la llegada de los niños y niñas indígenas a las escuelas criollas instaladas en cercanía de lo que fue el primer asentamiento qom. La entrevistada indígena y docente citada en el epígrafe describe el "gran impacto social, cultural, político, económico" sobre la vida del barrio en el que se asentaron y sobre las escuelas comunes a las fueron.

El artículo ofrece un recorrido histórico que va desde la llegada de los qom a Rosario, pasando por su visibilización y problematización social a fines de los años ochenta, el ingreso a la agenda de gobierno y la consecuencia normativa de creación de la Primera Escuela Primaria Bilingüe (Toba)65. Se hará fundamental hincapié en los actores intervinientes y en el proceso social inicial que desembocó en la decisión gubernamental de crear un establecimiento escolar destinado a las niñas y niñas indígenas de familias migrantes. El artículo se realiza con base al marco teórico-conceptual que aportan los estudios de política pública (SUBIRATS, KNOEPTEL, LARRUE y VARONNE, 2008; OSZLAK, O'DONNELL, 1981) con eje en la revisión de las siguientes fases del ciclo de la política pública: (i) surgimiento y percepción del problema, (ii) el ingreso a la agenda pública y (iii) la formulación y decisión del programa de la política. Las preguntas que ordenarán la exposición son las siguientes: ¿Cómo se enuncia entre los actores el problema social? ¿Cómo finalmente lo enuncia la normativa? ¿Cuál fue el proceso que permitió - por primera vez- convertir en problema público, la educación de los niños migrantes e indígenas de Rosario a fines de los años 80 y de principios de los 90? ¿Cómo surgieron en ese contexto los actores indígenas? ¿Qué luchas, tensiones, intereses de actores privados y factores colaborativos diversos confluyeron en las primeras fases del emergente ciclo de vida de la citada política?

En este sentido, los objetivos específicos de los que se ocupa el artículo son: i) analizar el modo en que el Estado procesa inicialmente el

${ }^{65}$ Coloco a manera de fórmula la frase Escuela Primaria Bilingüe (Toba), pues es el modo en que la denomina el Decreto 3346/90 de creación. 
cruce de demandas de inclusión social y étnica-cultural de migrantes internos indígenas a través de la educación, ii) identificar el modo en que los qom se configuran como actores, la relación con otros actores (criollos ${ }^{66}$ ) en términos de alianzas y resistencias, así como las estrategias para instalar temas en la agenda, iii) analizar el modo en que queda formulado el problema público en la normativa que crea a la primera Escuela Primaria Bilingüe (Toba) de Rosario.

La estrategia metodológica es de corte cualitativo. La información se construyó con base a cuatro fuentes: los actores indígenas y criollos relacionados a la creación de la primera Escuela Primaria Bilingüe (Toba), las observaciones de campo, la revisión bibliográfica y el análisis de normativas. Las entrevistas en profundidad y las observaciones de campo fueron resultado de un trabajo etnográfico realizado entre los años 2012 y 2014, en los barrios qom que alojan actualmente a las dos escuelas existentes de ElB67 - en Rosario-. En esa oportunidad se identificó a quienes formaron parte de la experiencia de la creación de la primera escuela.

Este artículo recoge parcialmente el contenido de uno de los capítulos de mi tesis doctoral68, la cual se llevó a cabo en el marco del PICT 2010 (ANPCYT FONCYT).

\section{LA EDUCACIÓN DE LOS NIÑOS Y NIÑAS QOM EN ROSARIO, SANTA FE (1986- 1990) DURANTE LAS PRIMERAS FASES DEL CICLO DE LA POLÍTICA PÚBLICA}

En el presente trabajo me detendré en el contexto, o proceso previo, en que se hizo lugar a la demanda de creación de la primera Escuela Primaria Bilingüe (Toba) de Rosario, provincia de Santa Fe, a través del citado Decreto 3346/9069. Retomaré con ese fin los años previos a la formulación de

\footnotetext{
${ }^{66}$ Refiere a los "no indígenas".

${ }^{67}$ En la actualidad son dos las escuelas existentes para atender la niñez indígena en Rosario.

68 La tesis con la que me doctoré en Ciencias Sociales fue defendida el 28 de septiembre de 2016, obteniendo la máxima calificación.

69 La fecha de la creación de la primera Escuela Primaria Bilingüe qom en Rosario, la cuestión indígena a nivel nacional ya había entrado a la agenda pública, primero por
} 
la mencionada norma para así aproximarme al modo en que se problematizó socialmente la educación de niñas y niños qom, y su ingreso a la agenda de la política pública santafesina.

Las primeras visitas al campo y el aporte de las fuentes secundarias sobre la creación de la citada escuela desembocaron en una temprana conjetura que más tarde fui consolidado: la existencia de una compleja configuración de intereses entre los vecinos criollos (antiguos residentes de un barrio -de la ciudad de Rosario- llamado Empalme Graneros) y los migrantes qom asentados en terrenos desocupados de ese barrio (padres, madres y referentes tratando de educar a niños y niñas de su comunidad). Es decir, intuía una constelación compleja de intereses entre los "establecidos" y los forasteros o "marginados", parafraseando a Norbert Elías (1998). Esto me interpeló sobre los motivos concretos de la política educativa destinada a las comunidades de pueblos indígenas en Rosario y sobre las verdaderas demandas que buscaron atender los actores públicos con esa política: zeran las demandas de los criollos establecidos o eran las de los migrantes marginados? ¿̇Cuál fue el proceso que permitió convertir en problema público a la educación de los niños migrantes e indígenas de Rosario entre fines de los años 80 y principios de los 90 ? ¿Cómo surgieron en ese contexto los actores indígenas? ¿Qué luchas, tensiones, e intereses de actores privados diversos confluyeron en las primeras fases del emergente ciclo de vida de la citada política?

El entramado de actores que construyeron la demanda no era justamente el de una convergencia solidaria entre ambos grupos, sino más bien todo lo contrario: criollos que no querían a los niños qom en las escuelas donde educaban a sus hijos y los qom que querían que sus hijos tuvieran una educación en su lengua y su cultura. Es decir, observaba que la primera Escuela Primaria Bilingüe (Toba) creada, como respuesta pública a las

medio de la mencionada Ley Nacional 23.302/85 de Política Indígena y Apoyo a las Comunidades Aborígenes y más tarde, por la adhesión al Convenio 169/89 (OIT). Sin embargo, aún no se había sancionado la Ley Federal de Educación № 24.195/92, que explícitamente reconocía al alumnado indígena en las escuelas. 
demandas, surgió no sólo como resultado de la lucha de la comunidad qom ${ }^{70}$, sino más bien de la convergencia de intereses entre actores contrapuestos, entre los indígenas y los vecinos criollos de Empalme Graneros. Por cierto, la decisión política dejaría, en el corto plazo, a ambos grupos medianamente satisfechos. Es decir, medianamente separados.

No obstante, deseo aclarar que en la fase de surgimiento y percepción del problema hay dos procesos simultáneos y emparentados entre sí: el de construcción de la migración qom como problema social en Rosario y el de la problematización social de la educación de los niños y niñas qom en las escuelas criollas de esa ciudad. Ambos procesos están presentes en el siguiente extracto del testimonio de una referente qom y maestra idónea:

Entonces los niños [que llegan a la escuela] son criaturas, con toda[s] las diferencia[s] sociales, rasgos faciales, costumbres [diferentes] y la ciudad se despierta y dice: - ¿qué hace[n]? (...) porque no existían indígenas para esta gente de la ciudad de Rosario, no existían... creyendo en la gran mentira, desde la conquista del desierto que fueron aniquiladas la[s] población[es] indígena[s] y no es así. Nosotros existíamos, entonces cuando vinimos aquí con nuestra familia, se dio un impacto social, cultural, político, económico, (...). Fue impactante la presencia indígena aquí en la ciudad y rotundamente negada (Maestra idónea, Escuela EIB No 1344 "Cacique Taigoyé", miembro del CIC, Barrio Empalme Graneros).

A fines de proceder al análisis diferenciaré ambos procesos comenzando por el primero: la construcción de la migración qom como problema social en Rosario. En la conjunción de las expresiones de la citada maestra idónea: "la ciudad se despierta y dice: - ¿qué hacen?" y "fue un impactante la presencia indígena aquí en la ciudad" se explicita la problematización social de la migración indígena en Rosario. Así, la conversión de un problema social a un problema público no se da sin lucha desde los actores privados y entre actores privados que compiten por definir el problema social que desean instalar en la agenda gubernamental. Lo cual

\footnotetext{
70 En estas primeras fases se presenta a la comunidad qom como un único grupo social, que constituye a su vez un único actor en el escenario que se analiza. Esta definición se asocia al grado de homogeneidad interna respecto a los objetivos e intereses que se buscan: la demanda de la primera escuela primaria bilingüe.
} 
a su vez implica la participación de los ciudadanos afectados (ZUBERO, 2014; ZICCARDI, 2004; ACUÑA y VACCHIERI, 2007).

La migración qom en Rosario constituyó avanzados los años 80 aquello que desde el análisis de políticas públicas se denomina problema público, en este caso particular, originado desde un problema social de progresivo dinamismo producto de los flujos continuos de migrantes indígenas a la ciudad, y con ellos la llegada de los niños a las escuelas criollas instaladas en cercanía del asentamiento. El "gran impacto social, cultural, político, económico" del que habla la entrevistada tiene que ver con los efectos que la llegada de los qom produce sobre la vida del barrio en el que se asentaron. Como fue mencionado en la Introducción, aun cuando la primera oleada migratoria qom del Chaco dataría de entre fines de los años 50 y principios de los 70, la literatura en la materia y las entrevistas realizadas, coinciden en que el asunto de la migración qom comienza a problematizarse socialmente recién con la llegada de la democracia. Uno de los maestros idóneos lo relata de la siguiente manera:

[El entrevistado refería a de dos de sus dirigentes indígenas ya fallecidos: Montiel Romero y Victoriano Arce] Pero el tema (...) que pasó que ellos no se identificaban [como tobas en] el año 74 , cuando ellos ya estaban. Y recién esto comienza a florecer en el año 80, 81; cuando hay una migración masiva acá a Rosario. (...) [Cuando] las comunidades del Chaco venían, pero en gran cantidad. En tren de carga (...). Entonces, de ahí.... cada vez venían más, y más. A veces venían treinta familias por semana. Y hasta que después comenzaron a venir muchos, muchos. Entonces, de ahí ven esta necesidad. Y ahí es como que recién ellos se empezaban a mover, (...). [Se empezaron a hacer] reconocer como pueblo indígena más que nada, con la llegada de la democracia (...) Porque aparte, estaba el tema de los militares (...). Eran todos militares, que a veces poco y nada a la gente indígena los querían (...). Entonces, comenzaron a hacer reuniones. Yo me acuerdo que hacían reunión ahí en la iglesia (...) Y bueno, ahí empezaron a... a decir esto, sobre el tema de vivienda, que estaban solicitando vivienda, que querían hacer esto... O sea: había muchas visiones de los ancianos, ¿̇viste? Pero, hasta hoy en día, una de todas esas se concretó en la escuela, y el barrio (Docente qom, Escuela 1333 "Nueva Esperanza", Barrio Toba Municipal).

El fragmento de entrevista reúne varios hechos cronológicos, todos relacionados entre sí: el ocultamiento de la identidad indígena durante la dictadura militar en Argentina, la llegada de la democracia, el 
autoreconocimiento de la identidad, la llegada a Rosario de los grupos más numerosos de las familias qom, la intensificación de los conflictos con los vecinos criollos de Empalme Graneros y las demandas al Estado local y provincial de vivienda y educación.

Un texto escrito desde los referentes de la comunidad se refiere al citado conflicto social suscitado entre criollos del barrio y los indígenas allí asentados. El mismo ubica el momento de mayor tensión entre los años 1986 y 1987, cuando los vecinos criollos del Barrio Empalme Graneros comienzan a problematizar la permanencia de la comunidad indígena en el lugar, contribuyendo a crear las condiciones para la incorporación de este asunto social a la futura agenda de problemas públicos de la ciudad. Esto permitió incidir en la relocalización posterior de parte del grupo. De acuerdo a los testimonios, la demanda realizada hacia la autoridad municipal por parte de los vecinos de Empalme Graneros fue la de un desalojo:

(...) la gente de Empalme Graneros empezó a hablar con el Intendente ${ }^{71}$ para que nos echen. Ellos no nos quieren ver y nos acusan que somos ladrones, tuberculosos, etc. (...). Está a la vista que el Intendente hizo caso a los vecinos, y nos han querido echar así nomás sin diálogo. Pero los indígenas pedimos dialogar con el Intendente, pero eso nos costó mucho. Pero después los indígenas tratamos de hablar con el diario la Capital para decirle que los indígenas no queremos salir de ese lugar y fue peor el enojo del Intendente, que amenazó echarnos con una máquina topadora, pero se arregló (...) Entonces el mismo intendente hizo un convenio con el ferrocarril para que nos trasladáramos a ese lugar donde estamos ahora [se refieren a la relocalización en el citado Barrio Toba Municipal en 1991] ${ }^{72}$ (Autoría colectiva qom, s/f).

El fenómeno que identifiqué como la convergencia de intereses divergentes entre actores contrapuestos se observa en la lógica secuencial

\footnotetext{
71 En ese momento el Intendente de Rosario era Horacio Uzandizaga (UCR). El mismo estuvo a cargo del gobierno municipal entre 1983 y 1987. Finalizado su primer período, fue reelegido. En 1989 presentó su renuncia y asumió como intendente interino Carlos Ramírez (UCR).

72 El Proyecto de Relocalización de la Comunidad Toba del Barrio Empalme Graneros, fue realizada por el Servicio Público de la Vivienda dependiente de la Secretaría de Promoción Social de la Municipalidad de Rosario. Los terrenos para la relocalización se situaron al sudoeste del Municipio de Rosario. El territorio que se destinó a la comunidad fue de veintidós hectáreas adquiridas a Ferrocarriles Argentinos, delimitado por las Avenidas Provincias Unidas y Circunvalación, las calles 1819 (en la actualidad "Aborígenes Argentino"), Felipe Moré y 1917. Para más detalles se puede ver Vázquez (2000, p. 157).
} 
de relaciones que plantea el fragmento citado: las presiones al intendente por parte de los criollos para que los desalojen; los intentos de desalojo por parte del Municipio; el pedido de diálogo por parte de los indígenas al intendente; la mediatización del problema social para influir en la opinión pública e incitar al intendente a intervenir; la relocalización de una parte de las familias. La última medida es la resolución política de los actores públicos al conflicto. No obstante, la secuencia demuestra cómo la resolución política es resultado de que el proceso pasara de ser un problema social a uno incluido en la agenda gubernamental, con la consecuente intervención pública al conflicto suscitado.

En otra de las entrevistas se relata una anécdota del año 86/87 aproximadamente, cuando un concejal del Municipio rosarino, vecino de Empalme Graneros, acompaña hasta el asentamiento qom a la policía, para presionar a uno de los referentes qom que actuaba como vocero de la comunidad, con el fin de que abandonaran el lugar. El referente detalla la estrategia que sirvió como recurso para instalar públicamente la situación que los qom atravesaban en Rosario, otorgándole simultáneamente mayor visibilidad a su cultura y a su lengua, a la que se le ataba la demanda por el derecho a la educación. La visita a radios, periódicos e incluso a otras escuelas criollas, fueron instrumentos estratégicos a la hora de la búsqueda de apoyos. Por ende, esa construcción de alianzas desde los qom con otros criollos traccionó también como recurso para lograr problematizar socialmente la cuestión. La instalación de la problemática en la agenda pública derivó, por cierto, en una mayor visibilización de los indígenas en Rosario. Según la información disponible, entre 1988 y 1989 el Intendente Usandizaga (UCR) acepta la demanda de los qom de hacerles viviendas a la comunidad; las mismas se harían efectivas en 1991, ya cuando Héctor Caballero (Partido Socialista) era Intendente de la ciudad (1989-1995). 
En otras palabras, en la historia causal73 del conflicto aparecen dos actores intencionales ${ }^{74}$ que operan en el origen del problema: los indígenas asentados en los terrenos baldíos del barrio Empalme Graneros y los vecinos criollos que rechazan su presencia en ese espacio. Ambos actores se reivindican el derecho a exigir que el gobierno intervenga para detener la problemática. Según algunos de los entrevistados indígenas, la organización vecinal Numain (Nunca más inundaciones) que demandaba la canalización de un arroyo, ${ }^{75}$ ubicado en el área del barrio, fue uno de los actores intencionales que generaron más presión sobre las autoridades municipales para que desalojaran a "los villeros de la zona". Entre otras argumentaciones, se señalaba que los indígenas se asentaban sobre el área de canalización del Arroyo, culpabilizándolos de las inundaciones de $1986^{76}$.

De este modo, las citadas inundaciones también incidieron en la construcción de la cuestión socialmente problematizada y en instalar definitivamente el "problema qom" en la agenda pública, lo cual muestra cómo convergen entre sí los actores con intereses divergentes y los factores o circunstancias especiales que potencian el conflicto. Para profundizar en este punto recuperaré empíricamente las dimensiones operativas del análisis de políticas públicas ${ }^{77} q u e$ permiten convertir un problema social en público (SUBIRATS et al, 2008). De este modo, la inundación emerge como un factor colaborativo, que a) intensifica el problema anterior sumándole mayor gravedad a las consecuencias de no atender el "problema qom"; b)

\footnotetext{
73 El concepto ha sido utilizado por Débora Stone (1989) con una definición muy similar a la de hipótesis causal.

74 Los actores intencionales son aquellos que intervienen materialmente en la lucha, diferenciándose de los actores empíricos que son "todos", incluso los potenciales.

75 Refiere al Arroyo Ludueña.

76 Elena Achilli también relata este proceso al que caracteriza como "un episodio de fuerte contenido prejuicioso". Y remarca que el mismo llegó a la plana de los medios gráficos (ACHILLI, 2003, p. 13).

77 Señalo las dimensiones operativas en itálica. La apreciación aquí realizada deviene de un análisis sintético y cruzado de actores, intereses, recursos y dimensiones operativas que aplican en la etapa de inclusión de un problema social en la agenda política. Las mencionadas dimensiones operativas parten de las nociones utilizadas en los análisis de casos de políticas públicas. Ver Subirats, Knoepfel, Larrue, Varonne (2008, p.132-135).
} 
potencia la visibilidad pública de la zona geográfica problemática. Así, el perímetro o audiencia del problema quedó visibilizado como el "asentamiento qom en el área de canalización del Arroyo Ludueña"; c) la inundación le otorga novedad a un problema que venía de tiempo atrás; d) la inundación genera una situación de crisis, otorgándole mayor urgencia al problema. Por ello logra sumar mayor impacto público y visibilidad donde los poderes públicos son forzados a responder de modo rápido. Así, el "tiempo reloj": "es urgente relocalizar a los qom", se convierte en un recurso a movilizar por parte de los actores públicos y privados. Los antecedentes bibliográficos refieren al hecho de la siguiente manera:

El drama vivido por los vecinos, asolados por las aguas, agudizaba las tensiones sociales que toda situación de contacto intercultural produce. Tal situación reforzaba el sentimiento de discriminación hacia los aborígenes ya existente entre los vecinos. Se los acusó de ser culpables de las inundaciones. Se los presentó como foco de infecciones contagiosas capaz de contaminar a sus vecinos (entre los tobas hay desnutrición, parasitosis, tuberculosis y mal de Chagas) (VÁZQUEZ, 2000, p. 156).

Si se observa con detenimiento el fragmento, la inundación opera como un factor democratizador del "drama vivido", es decir, lo sufren todos (criollos e indígenas). Sin embargo, agudiza la discriminación de unos (criollos) sobre los otros (indígenas). Los qom eran, para los criollos, sinónimo de "contagio de enfermedades", de "suciedad, del malvivir de los basurales" (ACHILLI, 2003, p.13). Así, el racismo78 de los establecidos opera como dispositivo organizador del resto de las clasificaciones sociales y emerge como impronta de origen, permeando el espacio territorial habitado y el espacio escolar.

\footnotetext{
78 La noción de racismo o raza está aplicada en el sentido en que Aníbal Quijano (2000) lo define. Así la raza se concibe como una construcción mental que opera como patrón de poder y jerarquía. El colonialismo es uno de los elementos constitutivos y específicos del poder mundial de poder capitalista y se funda en la imposición de una clasificación racial de la población del mundo, atravesando cada uno de los ámbitos, planos, dimensiones, materiales y subjetivas de la existencia cotidiana y a escala social. La raza aparece como eje organizador del resto de las clasificaciones sociales. Quijano agrega que "la raza" (y por ende el "racismo") se origina y mundializa a partir de América Latina, en el mismo momento y en el mismo movimiento histórico, en que el capitalismo se hace mundial.
} 
En lo que sigue incorporaré el segundo proceso: el de la problematización social de la educación de los niños y niñas qom

\begin{abstract}
[Cuando se asentaron las familias en Empalme Graneros] los padres [qom] empezaron a inscribir [a los niños] en las escuelas, escuelas cerquita. La escuela de Nicasio Oroño, la 66179 . Cuando metieron a esos niños, [los padres criollos] dicen: - no, indígenas no queremos, que se saquen a los niños indígenas ahí de los salones, no puede haber indígena en los salones. Entonces, las familias de los niños criollos de los barrios (...) empezaron a rechazar a los niños indígenas $\dot{\imath} Y$ qué hicieron los padres? Dijeron: nosotros, nuestros niños tienen que ir a la escuela porque es obligatoria (...) -¿Qué dijeron los padres?! ¿Qué hacemos? eran como 80 niños, y dejarlos a la deriva... bueno fueron al Ministerio pidieron educación para sus niños (...) ahí aprueban una escuela, una escuela puramente indígena qom (Maestra idónea, Escuela EIB $N^{\circ} 1344$ "Cacique Taigoyé", miembro del CIC, Barrio Empalme Graneros)
\end{abstract}

La escuela [surge] como una demanda de la comunidad, porque primero se hace esa demanda porque (...) cuando nace el pueblo acá (...) querían mandar (...) [a los hijos] a una escuela y acá en la zona hay muchas escuelas, pero resulta ser que los directores no aceptan. Directamente no aceptan a los hijos de indígenas y entonces, bueno, los papás, se pusieron de acuerdo, de por qué no pedimos una escuela para nosotros (...) y de ahí entonces surgió (...) los papás [indígenas] se organizan y hacen su pedido, su reclamo. Todo eso hacen al Ministerio, de ahí entonces el Estado acepta que tenga una escuela, si, una escuela (...) [según] la ley indígena, el Articulo 75 de parte cultural, lengua, y bueno ahí entonces nace la escuela (Referente qom, miembro del CEAPI, Empalme Graneros).

Con la interacción de ambos relatos se fortalece la hipótesis de la convergencia de intereses entre actores contrapuestos: (i) los padres criollos no quieren indígenas en las aulas y (ii) los padres indígenas demandan al Ministerio una escuela para sus hijos. La demanda de las familias qom hacia las autoridades del Ministerio de Educación y Cultura de la provincia de Santa Fe se formalizó vía trámite administrativo en 1988. En el fragmento que sigue se mantiene la misma idea, pero en este caso los actores que el entrevistado reconoce como clave son los "dos ancianos de la comunidad", o más precisamente la lucha que se hace a través de ellos:

\footnotetext{
79 Según datos que aporta Achilli esa situación de rechazo provocó que un grupo de esos niños continuara con su escolarización en el local de una iglesia (ACHILLI, 2003, p.13).
} 


\begin{abstract}
[Respecto al inicio de la lucha por tener una ElB80] (...) Habían...dos ancianos. Dos ancianos de la comunidad. (...) Que [eran] representante[s] legal[es] (...) que fueron capacitados como representantes de toda la república entonce [s] cuando... (...) yo luché en esta escuela (1333) fue a través de ellos! (...) Porque... \{iuy! Esta escuela tiene una historia muy larga y triste porque a nosotros[s], bueno...yo llevaba 18 chico[s] en un listado para que los recibieran. Me he ido a Granadero Baigorria, me ido a cerca de...Juan José Paso, en el campo (...) a toda' la escuela que están cercanas, y siempre me dijeron: "no hay lugar" en las escuelas criollas. Entonce' desde ahí vinimo' pensando los ancianos: - nosotro' tenemos que pedir al Ministerio, no sé dónde, pero nosotros tenemos que hacerlo.... Pero empezamo' a trabajar con la radio, con la televisión, a publicar lo que necesitamo', lo que yo necesito con los chico', toda esas cosas (Referente qom, Miembro del CIC, Barrio Toba Municipal).
\end{abstract}

La interpretación de la configuración inicial de la demanda educativa, como un proceso más bien de convergencia de intereses entre actores contrapuestos -o en su defecto de convergencia de intereses divergentes- no contradice los informes de investigación existentes ${ }^{81}$ sobre la lucha qom por la educación, sino que la complejiza. En la definición del problema social y la conceptualización que se desprenden de los testimonios, emergen las representaciones, los intereses y los recursos con que los actores intencionales concurren o intervienen en ese escenario. En el último fragmento de entrevista "los dos ancianos" operan como actores intencionales, a los que hay que sumarle complementariamente las variantes mencionadas en los testimonios anteriores: "la comunidad", "los padres" y algunos criollos que también los apoyaron82. En el último testimonio se observa, además, a los medios como actores intervinientes y a la mediatización como recurso para instalar (en la agenda gubernamental) la demanda educativa.

Cabe una última reflexión sobre el modo en que la historia causal del conflicto derivó en la hipótesis causal dominante en el Decreto 3346/90 de

80 Obsérvese que al momento de iniciar las demandas aún no se hablaba de Educación Intercultural Bilingüe (EIB) sino más bien de educación bilingüe para niños de la comunidad toba.

${ }^{81}$ Me estoy refiriendo concretamente a los trabajos de Liliana De Pino (1996) y Elena Achilli (2003). Del Pino fue la primera maestra de grado y luego vicedirectora del Anexo de la primera Escuela Primaria Bilingüe $N^{\circ} 1333$. Más tarde será la directora de la segunda Escuela Primaria Bilingüe $N^{\circ} 1344$, ubicada en el Paso y los Andes, en la zona de Empalme Graneros. Me explayaré sobre esto más adelante.

82 Entre esos actores aparece de modo reiterado Liliana De Pino. 
creación de la primera Escuela Primaria Bilingüe (Toba). Como ya mencioné, esa normativa sostiene que la creación de la Escuela $N^{\circ} 1333$ se realiza en respuesta a las demandas planteadas "por los integrantes de la Comunidad Toba, 83 ante la existencia de un elevado número de niños de edad escolar que no reciben asistencia educativa por carencia de establecimientos con capacidad edilicia suficiente para absorberlos84". La hipótesis causal en la norma omite referencia alguna a todo conflicto entre actores criollos e indígenas y asume como situación inaceptable el "elevado número de niños" sin asistencia educativa y "la carencia de establecimientos con capacidad edilicia". En esos términos la definición pública del problema logra ser controlada por la normativa85 quedando como único actor demandante la Comunidad Toba. Es este punto del Decreto que he puesto en discusión en el marco de las entrevistas. Los testimonios niegan que los establecimientos no tuvieran capacidad de albergar a los niños, más bien se trataba "del racismo de los criollos", en un contexto donde la escuela común tampoco tenía herramientas para educar a los niños qom.

\section{CONSIDERACIONES FINALES}

A modo de síntesis, el artículo describe y analiza los orígenes de la construcción y definición del problema social de la migración qom en Rosario. Durante ese proceso estuvieron presentes actores criollos que resistían la presencia indígena en el barrio y en la escuela, colaborando desde su rechazo en la configuración del asunto como cuestión socialmente problematizada. Las inundaciones en la zona del asentamiento en 1986 también actuaron como factor colaborativo, incidiendo definitivamente en que el problema social se convierta en problema público. De este modo, las

\footnotetext{
83 La mayúscula es del original.

${ }^{84}$ La itálica es mía y responde a la necesidad de resaltar el argumento normalizador del problema -que se elige explicitar en la norma-, ocultando el racismo de los sectores blancos del barrio Empalme Graneros.

85 Lo que es "controlado por la norma" alude al modo en que se narra el problema público. Es decir, la narrativa que finalmente se impone por parte del Estado y que los beneficiarios en función de sus intereses y valores, en mayor o menor medida, aceptan.
} 
demandas de acción pública realizadas por la comunidad qom, se vieron fortalecidas en el requerimiento de una resolución adecuada. La demanda de vivienda se atendió, en parte, con el Proyecto de Relocalización de la Comunidad en el Barrio Toba Municipal. Por otro lado, el Decreto 3346/90 vino a dar respuesta pública a la demanda educativa. Ambas respuestas han sido resultado de un fenómeno que he denominado convergencia de intereses divergentes entre actores contrapuestos.

Finalmente, aun cuando el Barrio Toba Municipal y la Escuela Primaria Bilingüe (Toba) respondieran a demandas de las comunidades indígenas, la fragmentación territorial y escolar que el Estado legitimó con sus medidas (un barrio para los qom/una escuela para los qom) ocultó el racismo desplegado por los sectores criollos y, por cierto, no propició espacio alguno de interrelación entre las matrices culturales que representaban a cada grupo. Así, al quedar normalizado el problema público educativo como "carencia de establecimientos con capacidad edilicia suficiente" para absorber a los niños indígenas, el Estado provincial redujo discursivamente el racismo criollo y lo ocultó en la práctica.

En todo el proceso que relaté, los enunciados y las prácticas discriminatorias del que fue objeto la comunidad qom y sus niños y niñas siguen muy presentes en la memoria de los entrevistados, tanto en los actores indígenas como en los criollos que los acompañaron en ese trayecto histórico (1986-1990). Además, el racismo, sigue presente en la actualidad. La persistencia del racismo en la sociedad y por ende, en los distintos ciclos de las políticas públicas es, por acción o por omisión, una práctica que el Estado legitima cuando no opera sobre la sociedad culturalmente hegemónica.

\section{REFERENCIAS}

ACHILLI, E. Tobas en la ciudad: sus luchas por la educación. Rosario: Universidad Nacional de Rosario, Facultad de Humanidades y Artes, CeaCu, 2003.

ACUÑA, C. H., VACCHIERI, A. (Comps.). La incidencia política de la sociedad civil. Buenos Aires: Siglo Veintiuno, 2007. 
DE PINO, L. A. La escuela bilingue Toba No 1333 Dalagayg Quitag (Nueva Esperanza). En L. A. DE PINO Y F. NELIR DALOSTTO, Las escuelas bilingües toba y mocoví. Rosario: AMSAFE, 1996.

ELÍAS, N. "Ensayo acerca de las relaciones entre establecidos y forasteros". En V. Weiler (comp.) La Civilización de los Padres y otros Ensayos (pp. 219-251). Santa Fe de Bogotá: Norma, 1998.

OSZLAK, O. Y O'DONNELL, G. Estado y Políticas Estatales en América Latina: Hacia Una Estrategia De Investigación. CLACSO, 4, Buenos Aires, 1981.

QUIJANO, A. "Colonialidad del poder y clasificación social". Journal of WorldSystem Research, Riverside, California, Vol. VI, Nro. 2, 2000.

STONE, D. A. "Causal Stories and the Formation of Policy Agendas". Political Science Quarterly, Vol. 104, No. 2, pp. 281-300, 1989.

SUBIRATS, J, KNOEPFEL, P, LARRUE, C, Y VARONNE, F. Análisis y gestión de políticas públicas, Barcelona: Editorial Ariel, 2008.

TAMAGNO, L. y MAFFIA. M. "Lo afro y lo indígena en Argentina. Aportes desde la antropología social al análisis de las formas de la visibilidad en el nuevo milenio", 2, n.63, pp.121-141, Boletín Americanista, Añolxi, Barcelona, 2011.

VAZQUEZ, H. P. Procesos Identitarios y exclusión sociocultural. La cuestión indígena en la Argentina. Bs. As. Ed. Biblos, 2000.

ZICCARDI, A. (Coord.) Participación ciudadana y políticas sociales en el ámbito local. México: Instituto Nacional de Desarrollo Social, 2004.

ZUBERO, I. Participación, ciudadanía y exclusión social. Educación Social. Revista de Intervención Socioeducativa. 57, 67-80, 2014.

Instrumentos de Derecho Internacional

OIT (1989) Convenio № 169 sobre Pueblos Indígenas y Tribales en Países Independientes.

\section{Legislación Nacional sobre EIB:}

Constitución Nacional de la República Argentina (1994)

Documento La Modalidad de Educación Intercultural Bilingüe en el Sistema Educativo Nacional, Consejo Federal de Educación (2010)

Ley de Educación Nacional Nº 26.206 (2006)

Resolución 107 del Consejo Federal de Cultura y Educación (1999)

Resolución Nº549 del Ministerio de Educación Ciencia y Tecnología de la República Argentina (2004)

Resolución № 105 del Consejo Federal de Cultura y Educación (2010)

Legislación de la provincia de Santa Fe

Ley N ${ }^{\circ}$ 10375/89. Pcia. Santa Fe. - Adhesión a Ley Nacional Nº 23302 de Protección a Comunidades Aborígenes 
Decreto No 3346/90 - Creación de Escuela Primaria Bilingüe (Toba) № 1333, Barrio Empalme Graneros. Rosario

Ley $N^{\circ} 10701 / 91$ - Creación de escuela de educación inicial, pre primaria y primaria de Comunidad Mocoví. Recreo. Santa Fe.

Ley No 11078/94 - Comunidades Aborígenes. Creación del Instituto Provincial de Aborígenes Santafesinos (IPAS).

Decreto No 2200/98 Creación -con retroactividad al 3 de agosto de 1993- de "la Escuela Primaria Bilingüe (Toba)", N¹344. Rosario.

Decreto No 1719/2005 - Aprobación del Reglamento para la Organización y Funcionamiento de las Escuelas de Educación Intercultural Bilingüe (EIB).

Recebido em: Setembro de 2016

Aceito em: Novembro de 2016 